\title{
The effect of intensity during sequential alternation of unilateral amygdaloid stimulation
}

\author{
JOHN GAITO \\ York University, 4700 Keele Street, Downsview, Ontario, Canada MSJ 1PS
}

\begin{abstract}
Previous research indicated that an oscillation effect resulted during sequential alternation of unilateral amygdaloid stimulation, with consistent low-latency values in one side and consistent high values in the contralateral side. The effect of intensity $(100,280,560$ microA) was investigated in this study. The oscillation tendency was similar to that in previous research with 100 - and 280 -microA intensities. However, 560-microA intensity tended to disrupt the oscillation tendency moderately.
\end{abstract}

The "kindling effect" has been investigated in a number of laboratories as a model of learning, a model of epilepsy, or as an example of behavioral interest in its own right (e.g., Gaito \& Gaito, 1974; Goddard, McIntyre, \& Leech, 1969). This event involves a change from normal exploration (Stage 1-NE) to behavioral automatisms (Stage 2-BA, chewing, eye closure on ipsilateral side, salivation) and, finally, to clonic convulsions (Stage 3-CC) in response to electrical stimulation of a specific brain site (e.g., amygdala). Stage 3 behavior involves the rat standing on its hind paws, and bilateral convulsions of the forelimbs ensue.

In recent research in our laboratory using a sequence of alternating unilateral stimulations of the amygdala, an "oscillation effect" was observed (Gaito, 1976e). This oscillation usually involved consistently low values for the amygdala first stimulated (primary site) and consistently high values for the contralateral amygdala (secondary site). The effect was most prominent in latency data (number of seconds from onset of stimulation to onset of convulsion). Bilateral stimulation prior to the development of oscillation, or after it was prominent, produced little effect on this oscillation tendency (Gaito, 1976a), as was also the case with number of trials per day [1, 3, 6 (Gaito, 1976c)] and number of convulsions per phase $(1,6,12$ (Gaito, 1976b)]. Oscillation was as prominent in old rats (420-475 days of age) as in younger ones (135-200 days) (Gaito \& Nobrega, 1976) and rest intervals of 1,3 , and 6 months interspersed between two sets of 10 sequential alternation phases had no deleterious effect (Gaito, 1976d). In the present experiment, the effect of intensity of stimulation on the oscillation tendency was investigated.

\section{METHOD}

Twenty-eight male Wistar rats (approximately 150 days of age) were implanted bilaterally in the amygdalae with bipolar electrodes (nichrome wire with trimel coating, $.127 \mathrm{~mm}$ in diam, dipped one time in Epoxylite, heated $1 \mathrm{~h}$ at $60^{\circ} \mathrm{C}$ ). The brain coordinates for electrode implantation were the same as in previous experiments: $.5 \mathrm{~mm}$ posterior to bregma, $4.5 \mathrm{~mm}$ from midline, $8.5 \mathrm{~mm}$ from skull (Gaito , 1976e; Gaito \& Gaito, 1974).

Seven or more days after surgery, brain stimulation began. Each rat in one group of eight (Group 1) was stimulated with a Lafayette stimulator three times each day $(1 \mathrm{~h}$ between trials) for $30 \mathrm{sec}$ with a $60-\mathrm{Hz}$ sine wave of $100 \mu \mathrm{A}$ (peak to peak) until six convulsions resulted. The number of trials to reach this criterion was recorded, as was the latency and duration of the convulsion. On each trial, stimulation terminated after $30 \mathrm{sec}$ (if a convulsion was in progress or if no convulsion had occurred) or at the termination of the convulsion (if the convulsion ceased prior to $30 \mathrm{sec}$ ). On the day after the sixth convulsion, stimulation began at the secondary site and continued until six convulsions occurred. Then stimulation was again instituted at the primary site, etc. This sequential alternation of unilateral stimulation was continued for 10 phases.

In Group 2, seven rats were stimulated three trials per day $(1 \mathrm{~h}$ between trials) until six convulsions occurred in each of 10 alternating phases; the intensity of stimulation was $280 \mu \mathrm{A}$. In Group 3,13 rats were treated in similar fashion at an intensity of $560 \mu \mathrm{A}$.

\section{RESULTS}

The results for the three groups are shown in Tables 1 and 2 for two dependent variables over 10 phases: latency (number of seconds between onset of stimulation and onset of CC) and criterion (number of trials to $6 \mathrm{CCs}$ ). Duration of convulsion data were not

Table 1

Number of Oscillators for the Three Groups

\begin{tabular}{cccc}
\hline & $\begin{array}{c}\text { Group 1 } \\
100 \mu \mathrm{A}\end{array}$ & $\begin{array}{c}\text { Group 2 } \\
280 \mu \mathrm{A}\end{array}$ & $\begin{array}{c}\text { Group 3 } \\
560 \mu \mathrm{A}\end{array}$ \\
\hline & \multicolumn{3}{c}{ Criterion } \\
PO & 3 & 2 & 4 \\
SO & 2 & 2 & 0 \\
NO & 3 & 3 & 9 \\
& & Latency & \\
PO & 5 & 4 & 5 \\
SO & 3 & 3 & 4 \\
NO & 0 & 0 & 4 \\
\hline
\end{tabular}

Note $-P O=$ primary oscillation, $S O=$ secondary oscillation, $N O=$ nonoscillation 
Table 2

Means for the Three Intensities Over 10 Phases

\begin{tabular}{rrrrrrrrrrr}
\hline \multicolumn{10}{c}{ Phases } \\
& 1 & 2 & 3 & 4 & 5 & 6 & 7 & 8 & 9 & 10 \\
\hline \multicolumn{10}{c}{ Criterion } \\
$100 \mu \mathrm{A}$ & 18.3 & 18.1 & 6.6 & 9.0 & 6.8 & 12.3 & 7.1 & 8.3 & 7.6 & 7.5 \\
$280 \mu \mathrm{A}$ & 15.1 & 12.9 & 6.7 & 8.7 & 7.7 & 8.1 & 7.3 & 6.4 & 6.4 & 6.6 \\
$560 \mu \mathrm{A}$ & 9.6 & 10.0 & 6.2 & 6.9 & 6.1 & 7.6 & 6.1 & 6.6 & 6.0 & 6.0 \\
& & \multicolumn{10}{c}{ Latency } \\
$100 \mu \mathrm{A}$ & 6.8 & 9.6 & 5.9 & 10.7 & 7.8 & 11.8 & 9.5 & 11.9 & 9.1 & 12.5 \\
$280 \mu \mathrm{A}$ & 10.3 & 8.8 & 6.7 & 7.4 & 8.0 & 7.0 & 8.3 & 7.2 & 9.4 & 5.7 \\
$560 \mu \mathrm{A}$ & 6.6 & 6.1 & 3.6 & 6.2 & 3.5 & 5.4 & 3.7 & 5.3 & 3.5 & 3.6 \\
\hline
\end{tabular}

Note-Latency measured in seconds. Criterion-number of trials to 6 CCs.

analyzed because the previous research (Gaito, 1976e) indicated few cases of oscillation in this dependent variable. As in previous work, an oscillation effect appeared which was stronger in latency than in criterion data. In the three groups, the numbers of oscillators in the latency data were eight, seven, and nine, respectively. Thus, 24 rats oscillated out of the 28 rats which completed the 10 phases. Only 13 rats oscillated in criterion data.

In latency data there were 14 primary oscillators (low values in primary site, high values in secondary site) and 10 secondary oscillators (high values in primary site, low values in secondary site). For criterion data there were nine primary oscillators and four secondary oscillators.

No statistical analyses were attempted to compare the three groups relative to the number of oscillators. However, there is the suggestion that oscillation is less apt to result with high intensity $(560 \mu \mathrm{A})$. The high intensity appeared to prevent oscillation more in the criterion measure than in latency data, with only 4 of 13 rats oscillating. Likewise, four rats did not oscillate in latency data. In general, primary oscillation predominated in all groups. This predominance is consistent with that found in previous research using 100- $\mu \mathrm{A}$ intensity.

The means for the 10 phases are shown in Table 2. The number of trials to the criterion of $6 \mathrm{CCs}$ was greatest in Phases 1 and 2, with a sharp decrement thereafter. Latency means were more consistent over the 10 phases than were the criterion means. The means for the high-intensity group were lower than those for the other groups in 9 of the 10 phases for the criterion measure; the discrepancy was greatest during Phases 1 and 2 . In the latency dependent variable, the highintensity means were lowest for all phases.

In the high-intensity group, it was observed that the severity of convulsion was greater, with more violent overall behavior and more frequent squealing. Pinel, Phillips, and Deol (1974) reported that high-intensity stimulation $(500 \mu \mathrm{A})$ produced more severe motor seizure patterns and hastened the kindling process. Our results (Table 2) also showed that rats with $560-\mu \mathrm{A}$ stimulation completed the 10 phases more quickly than did the lower intensity groups. More rats achieved the criterion in the minimum number of trials (6) or convulsed immediately upon onset of stimulation with the high-intensity stimulation. These aspects are probably the basis for the decreased tendency to oscillate. The number of oscillators over both measures for Groups 1, 2, and 3, respectively, was 13 (of 16), 11 (of 14), and 13 (of 26).

Table 3 provides examples of oscillatory and nonoscillatory behavior. Rat 1 (Group 1) showed primary oscillation in both latency and criterion data. Rat 17 (Group 2) was a secondary oscillator in the latency measure, but did not oscillate in criterion data. Rat 12 (Group 3) did not oscillate in either dependent variable.

\section{DISCUSSION}

These results are consistent with the previous ones which demonstrated the oscillation tendency and suggested its authenticity. This tendency appears to be a prominent feature of unilateral sequential alternations and is not due to poorly placed electrodes in one of the two sites (Gaito, 1976a, e). The evidence for this point is the following.

1. In the first study (Gaito, 1976e), histological analyses were conducted on most of the rats. Placement of the electrodes appeared not to be related to oscillation or nonoscillation behavior. For example, some rats with electrodes in the same amygdaloid nucleus on both sides showed oscillation in both latency and criterion data; some oscillated in only one of the two; some did not oscillate in either dependent variable. Likewise, if one electrode was in the amygdala and the other was outside, oscillation resulted but not in the fashion expected. For example, one rat required an extreme number of trials (50) to achieve the criterion of $6 \mathrm{CCs}$ for the first side stimulated; the electrode was in the caudate putamen/globus pallidus area. Even though this electrode was not in the amygdala and the kindling rate was slow, latency was lower on this side than on the contralateral side (electrode in the amygdala), and primary oscillation resulted. In this case, if the misplaced electrode was the basis for the oscillation effect, secondary oscillation should have occurred.

2. If a misplaced electrode was the basis for oscillation, one

Table 3

Results (Means) for One Rat in Each Group

\begin{tabular}{|c|c|c|c|c|c|c|c|c|c|c|}
\hline & & & & Pha & & & & & & \\
\hline & 1 & 2 & 3 & 4 & 5 & 6 & 7 & 8 & 9 & 10 \\
\hline & & & roup & $1(10$ & $\mu \mathrm{A}$, & Rat 1 & & & & \\
\hline Latency & 3.5 & 8.3 & 4.0 & 12.0 & 4.0 & 11.7 & 5.8 & 13.5 & 7.5 & 13.3 \\
\hline Criterion & 15 & 24 & 6 & 14 & 6 & 10 & 7 & 8 & 6 & 8 \\
\hline & & & oup 2 & $(280$ & $\mu \mathbf{A}$ & Rat 1 & & & & \\
\hline Latency & 6.2 & 3.3 & 3.7 & 2.8 & 4.0 & 1.7 & 4.2 & 1.0 & 3.7 & 1.2 \\
\hline Criterion & 9 & & 6 & & 6 & 6 & 6 & 6 & 6 & 6 \\
\hline & & & oup 3 & $(560$ & $\mu \mathrm{A}$, & Rat 1 & & & & \\
\hline Latency & 10.8 & 4.5 & 2.3 & 1.3 & 1.2 & 1.0 & 1.0 & 1.0 & 1.0 & 1.0 \\
\hline Criterion & 16 & 6 & 8 & 6 & 6 & 6 & 6 & 6 & 6 & 6 \\
\hline
\end{tabular}

Note-Latency measured in seconds. Criterion-number of trials to 6 CCs. 
would expect that both criterion and latency data would show the same oscillation pattern. However, this possibility does not occur consistently. Usually, oscillation is present in latency data but not in the criterion measure, and on some occasions primary oscillation will ensue in one measure while secondary oscillation occurs in the other.

3. Oscillation usually commences as of Phase 1 . However, a number of rats do not begin the oscillation pattern until Phase 3 or later. In some rats run for 20 or more phases, oscillation began as late as Phase 11 (Gaito \& Nobrega, 1976).

4. A number of rats show mixed patterns of oscillation. For example, one rat was run for 32 phases, showing nonoscillation over the first 8 phases, secondary oscillation for 10 phases, and primary oscillation for the last 14 phases (Gaito \& Nobrega, 1976).

5. If a misplaced electrode is involved, oscillation should not occur after five phases of bilateral stimulation, because such stimulation brings rats to quick attainment of the criterion, viz., in six trials for most rats, and to low values for latency. Yet bilateral stimulation has little effect on oscillation in the latency data (Gaito, 1976a).

6. Furthermore, oscillation should occur over only a few phases and then disappear, because periodic stimulation lowers the threshold for seizure and both sides should become equally efficient (Tress \& Herberg, 1972). However, although there are a few rats which terminate oscillation after a few phases, most continue to oscillate throughout the entire series of phases, especially in the latency measure.

Another possible explanation for oscillatory behavior is related to the use of the same intensity of stimulation for both amygdalae. One might argue that the oscillation results are based on differential thresholds in the two amygdalae. Thus, the same intensities in both amygdalae would result in the CC condition being effected more efficiently for one amygdala than for the other one. However, research using intensities just above threshold for each amygdala indicates that oscillation is still prominent in latency data.

That the oscillation effect is an authentic phenomenon is suggested by other researchers. McIntyre (1975) and McIntyre and Goddard (1973) reported latency values of primary oscillation nature for groups of rats over three phases of sequential alternation. Individual data were not shown. Presumably, some secondary oscillators were present but primary oscillation predominated overall, as in our research.

As in previous research (Gaito, 1976a, c), there was the suggestion that an active inhibitory process is generated during unilateral stimulation which affects that site or the contralateral site during subsequent stimulations. For example, Rat 20 of Group 2 reared on hind paws quickly and began to $\mathrm{CC}$ within a few seconds when stimulating the primary site. When stimulating the secondary site, however, a complete CC did not result until after about $7 \mathrm{sec}$ had elapsed. In some cases, the front paws would move slightly, as if the $\mathrm{CC}$ was beginning, but the move- ment would terminate within 1 or $2 \mathrm{sec}$. The rat appeared to be actively inhibited during this state of suspension prior to convulsing. The appearance of active inhibition seems to be further evidence for the authenticity of oscillation. Research under way involving a more detailed recording and analysis of these "incomplete CCs" indicates that CCs occur most frequently on the side showing the greatest latency value.

\section{REFERENCES}

Garto, J. The effect of bilateral stimulation during sequential alternation of unilateral amygdaloid stimulation. Bulletin of the Psychonomic Society, 1976, 4, 355-357. (a)

GaITo, J. The effect of number of convulsions per phase on the oscillation tendency. Bulletin of the Psychonomic Society, 1976, in press. (b)

GaITo, J. The effect of number of trials per day during sequential alternation of unilateral amygdaloid stimulation. Bulletin of the Psychonomic Society, 1976, 4, 403-404. (c)

GaITo, J. The effect of varying rest intervals following the development of oscillation during unilateral amygdaloid stimulation. Bulletin of the Psychonomic Society, 1976, in press. (d)

Garto, J. An oscillation effect during sequential alternations of unilateral amygdaloid stimulations within the kindling paradigm. Physiological Psychology, 1976, 4, 303-306. (e).

Garto, J., \& Garto, S. T. Interanimal negative transfer of the kindling effect. Physiological Psychology, 1974, 2, 379-382.

Garto, J., \& Nobrega, J. The oscillation effect during sequential alternation of amygdaloid stimulation with aged rats. Bulletin of the Psychonomic Society, 1976, in press.

Goddard, G. V., McInTYRe, D. C., \& LeEch, C. K. A permanent change in brain function resulting from daily electrical stimulation. Experimental Neurology, 1969, 25, 295-330.

MCINTYRE, D. C. Split-brain rat: Transfer and interference of kindled amygdala convulsions. Canadian Journal of Neurological Sciences, 1975, 2, 429-437.

MCINTYRE, D. C., \& GODDARD, G. V. Transfer, interference and spontaneous recovery of convulsions kindled from the rat amygdala. Electroencephalography and Clinical Neurophysiology, 1973, 35, 533-543.

Pinel, J. P. J., Phillips, A. G., \& Deol, G. Effects of current intensity on kindled motor seizure activity in rats. Behavioral Biology, 1974, 11, 59-68.

Tress, K., \& Herberg, L. J. Permanent reduction in seizure threshold resulting from repeated electrical stimulation. Experimental Neurology, 1972, 37, 347-359.

(Received for publication August 19, 1976.) 